\title{
Predicting effects of rainforest fragmentation from live trapping studies of small mammals in Sri Lanka
}

\author{
Mayuri R. Wijesinghe \\ Department of Zoology, University of Colombo, Cumaratunga Munidasa Mawatha, Colombo 03, Sri Lanka \\ Email: mayuri@zoology.cmb.ac.lk
}

Date of publication (online): 26 June 2012 Date of publication (print): 26 June 2012 ISSN 0974-7907 (online) | 0974-7893 (print)

Editor: Giovanni Amori

Manuscript details:

Ms \# 02994

Received 08 November 2011

Final received 23 May 2012

Finally accepted 29 May 2012

Citation: Wijesinghe, M.R. (2012). Predicting effects of rainforest fragmentation from live trapping studies of small mammals in Sri Lanka. Journal of Threatened Taxa 4(6): 2629-2636.

Copyright: () Mayuri R. Wijesinghe 2012 Creative Commons Attribution 3.0 Unported License. JoTT allows unrestricted use of this article in any medium for non-profit purposes, reproduction and distribution by providing adequate credit to the authors and the source of publication.

Author Details: DR. MAYURI R. WIJESINGHE is a Senior Lecturer in Zoology attached to the University of Colombo, Sri Lanka. Her expertise lies in the fields of Conservation Biology and Toxicology. Her research focuses on collecting baseline data on the distribution and habitat requirements of many rodents and shrews and on investigating reasons for their vulnerability to forest destruction and fragmentation. She also studies the impact of agrochemicals and heavy metal pollutants on the survival, growth, development and histopathology of larval stages of amphibians.

Acknowledgments: I am very grateful to the National Science Foundation for granting financial assistance (2004/Zoo/B2) for this project. I am also thankful to the Forest Department and the Department of Wildlife Conservation for granting me permission to work in the selected forests.

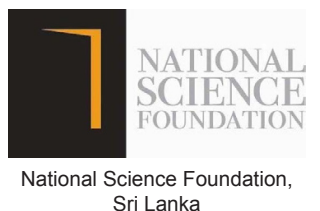
Sri Lanka

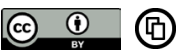

OPEN ACCESS | FREE DOWNLOAD

\begin{abstract}
This paper examines the impact of forest fragmentation on small mammals inhabiting the rainforests of Sri Lanka. Fifteen forests ranging in size from 145 to 11000 ha were live-trapped for five to eight nights each in both interior and edge habitats, yielding a total of 18400 trap nights. A total of 444 individuals belonging to 10 species of small mammals were captured. Multiple-regression analysis incorporating three indicators of fragmentation: patch area, shape index (perimeter/area) and degree of isolation, showed no significant effects on overall species richness of small mammals. This is likely because the decline of forest-adapted species from small forest fragments was accompanied by an increase in more tolerant and adaptive species. Patch size, however, had a significant positive effect on the abundance of small mammals. Of the two dominant species, the endemic Mus mayori was positively affected by patch area whilst Rattus rattus was not affected. Although no differences were evident between interior and edge habitats with respect to total species richness and abundance, endemics were more abundant in core areas while the reverse was true for the nonendemics. Core forest areas were significantly different from forest edges with respect to canopy cover, density of herbaceous vegetation, large trees and litter cover. These results suggest that forest fragmentation is detrimental to some forest specialists and beneficial to some generalists.
\end{abstract}

Keywords: Edge effects, endemics, fragmentation, rainforests, small mammals, Sri Lanka.

\section{INTRODUCTION}

The global decline of biodiversity has been primarily attributed to habitat loss and fragmentation of natural landscapes. Not surprisingly, many studies have focused on the effects of forest fragmentation on the distribution and abundance of different animal taxa (Walters 1991; Boone $\&$ Keller 1993; Malcolm 1994). Forest destruction and fragmentation may affect fauna in several ways. As forests become increasingly fragmented the smaller remnant patches support fewer species (e.g. Debinski \& Holt 2000; Laurance et al. 2000; Cox et al. 2004). The creation of edge habitats at the interphase where the forest meets man-modified habitats facilitates invasion of competitors or predators and/or exposes forest species to unsuitable external environmental conditions (Yahner 1988); a linear forest would be exposed to greater edge effects than a circular forest patch having the same area. Also, as forests become increasingly isolated, inter-patch migration becomes more difficult. This factor is particularly important for faunal taxa that have a metapopulation structure which necessitates frequent mixing of populations between different forest patches (Diffendorfer et al. 1995). Based on these factors it could be predicted that small, isolated and irregularly-shaped forests would support the lowest faunal diversity. However, all species are not equally sensitive to habitat fragmentation. For example species vulnerability to 
forest fragmentation depends on habitat preferences (Andrén 1994). Generalist species, capable of using the original forest, its borders and the surrounding matrix, are less affected than species restricted to the use of the forest alone.

The tropical rainforests in southwestern Sri Lanka harbour a rich complement of flora and fauna, with a large proportion of species being endemic to the island. Because of high levels of endemism and the exceptional levels of threat facing the biota, the wet zone in the southwest of the country has been recognized as a biodiversity hotspot (Myers 1990; Myers et al. 2000). Southwestern Sri Lanka, together with the Western Ghats of India, has the highest human population density among the hotspots (Cincotta et al. 2000). Increasing human settlements, urbanization and agricultural expansion has resulted in intense habitat degradation and fragmentation of the once extensive forests, which now cover a mere eight per cent of Sri Lanka's wet zone land area. So far, no study has attempted to examine the influence of spatial attributes of forest fragments and/or edge effects on the fauna inhabiting these rainforests in Sri Lanka.

The present live trapping study aimed to investigate the effects of forest area, shape, degree of isolation and the edge effects on species richness and abundance of small mammals in rainforest fragments of southwestern Sri Lanka with a view to ascertaining the overall effects of forest loss and fragmentation on this community. Small mammals are of special interest as they make a significant contribution to the country's biological diversity and endemism representing over 30 per cent of the mammals and over 60 per cent of the endemic mammals inhabiting the island.

\section{METHODS}

\section{Selected rainforests}

A total of 15 rainforests ranging in size from 145 to 11000 ha were surveyed for small mammals from 2006 to 2009 in: Kombala-Kottawa, Kanneliya, Dombagaskanda, Kalugala, Morapitiya, Delwala, Delgoda, Dellawa, Masimbula, Warathalgoda, Kalubowitiyana, Sinharaja, Walankanda, Yagirala and Kudumeriya in the four districts of Ratnapura, Kalutara, Galle and Matara in southwestern Sri Lanka. These are low to mid elevation forests with tropical wet evergreen forest vegetation (de Rosayro 1950). The forests are dominated by tree species of the family Dipterocarpaceae.

\section{Capturing small mammals}

Small mammal communities were assessed using live trapping. Two trapping grids were laid, one at the edge of the forest starting at the boundary (edge habitat) and the other in the forest interior at least $500 \mathrm{~m}$ away from the forest boundary (core habitat). Each trapping grid consisted of 50 Sherman's live traps laid at $10 \mathrm{~m}$ intervals and baited with lightly roasted coconut kernel. This method has been successfully used for live trapping small mammals in Sri Lankan rainforests in the past (Wijesinghe \& de Brooke 2005). Live trapping was conducted for five to eight nights twice or thrice during the study period yielding a total of 18400 trap nights. A live trapping of four nights has been recognized as being sufficient for the comparison of small mammal communities between forests (Wijesinghe 2010). Traps were checked and rebaited each morning and captured individuals were released at the point of capture after identification. Fur clipping enabled the identification of recaptured individuals within each trapping session of a maximum of eight days. The abundance of each species of small mammal was taken to be the number of new animals captured during each individual trapping session in a given forest, following Wijesinghe \& Brooke (2005), Molur \& Singh (2009), Ratnaweera \& Wijesinghe (2009), and Wijesinghe (2010).

\section{Fragmentation indices}

Information on patch size, length of periphery and the distance to the nearest forest fragment for the 15 surveyed forests was obtained from the most recent digital maps provided by the Forest Department, Sri Lanka. If a forest was connected to another forest, the degree of isolation was taken to be zero. The shape index for each of the forests was calculated according to Gkaraveli et al. (2001) where Shape index = Perimeter of fragment / Area of fragment.

\section{Habitat assessments}

A total of 10 microhabitat parameters were identified that could be potentially affected by fragmentation in each of the two trapping grids at the edges and core areas of the selected forests. They were 
canopy cover, number of seedlings (small plants below the height of $1 / 2 \mathrm{~m}$ ), number of non-woody herbaceous plants, number of trees with a girth at breast height (gbh) of less than $20 \mathrm{~cm}$, number of large trees (trees with over $20 \mathrm{~cm}$ gbh), litter depth, litter cover, light intensity, relative humidity and temperature at a height of one metre from the ground. These were measured in six $5 \times 5 \mathrm{~m}$ quadrats which were evenly distributed throughout each of the two trapping grids. The canopy was estimated cover using a plastic pipe (sighting tube with a diameter of $2.5 \mathrm{~cm}$ ), one end of which was covered by a piece of cellophane marked with a grid. When looking vertically upwards through the pipe towards the sky, the grid squares in which the view in at least half the area was intercepted by the canopy was counted and used to calculate the percentage canopy cover. Five readings were taken at the four corners and middle of each of the $5 \times 5 \mathrm{~m}$ quadrats. The number of seedlings, non-woody herbaceous plants, small tress and large trees were counted within each of the six 5x5 m quadrats. Litter depth was measured at the four corners and middle of each quadrat using a ruler. This also included the humus layer. The litter cover was estimated at the four corners and middle of each quadrat using a square mesh of $25 \times 25 \mathrm{~cm}$ with subdivisions of $5 \times 5 \mathrm{~cm}$ squares. The number of squares where more than half the square was covered by litter was counted and used to calculate the percentage litter cover. Temperature, relative humidity and light intensities (Yu Pung YF 172) were measured using standard portable meters (Yu Pung YF 180).

\section{RESULTS}

\section{The small mammal community in the wet zone forests}

A total of 444 individuals belonging to 10 species, eight rodents and two shrews, were recorded from the 15 rainforests. Five of these species Mus mayori Thomas, 1915 (Spiny Mouse), Srilankamys ohiensis Phillips, 1929 (Sri Lanka Bicolored Rat), Funambulus layardi Blyth, 1849 (Flame-striped Jungle Squirrel), Crocidura miya Phillips, 1929 (Sri Lanka Longtailed Shrew) and Suncus zeylanicus Phillips, 1928 (Sri Lanka Jungle Shrew) are endemic, with one of them (S. ohiensis) belonging to an endemic genus. The non-endemics recorded were Mus booduga Gray,
1837 (Field Mouse), Rattus rattus Linnaeus, 1758 (Common Rat), Vandeleuria oleracea Bennett, 1832 (Long-tailed Tree Mouse), Funambulus sublineatus Waterhouse, 1838 (Dusky-striped Jungle Squirrel) and Funambulus palmarum Linnaeus, 1766 (Palm Squirrel). The capture rate (number of captures per 100 trap nights was 3.09 per cent. The two predominant species $M$. mayori and $R$. rattus comprised 90 per cent of the small mammal community.

\section{Effect of forest fragmentation on small mammals}

Table 1 shows the summarized results of the trapping survey in the 15 forests. Multiple regressions were conducted incorporating the three indicators of fragmentation, i.e. the area, shape and the degree of isolation of the forests, as independent variables and species richness or abundance as the dependent variable. These analyses revealed that species richness was not significantly affected by any of the three factors (species richness $=-0.242+0.000025$ area 0.714 shape -0.0523 isolation; $\mathrm{F}=2.76, \mathrm{P}>0.05$ ), but that abundance was significantly and positively affected by patch size (abundance $=2.12+0.000148$ area -2.23 shape -0.161 isolation; $\mathrm{F}=5.92, \mathrm{P}>0.05$ ). The three fragmentation indices contributed to around $40 \%$ of the variation in species richness and to $60 \%$ variation in abundance. Contrasting trends were observed with the two predominant species. Multiple-regressions incorporating abundance of the endemic $M$. mayori showed that around $80 \%$ of the variation in abundance was explained by the three factors with patch size having a positive and significant influence (M. mayori $=0.705+.000095$ area -0.846 shape -0.0947 isolation; $\mathrm{F}=16.74, \mathrm{P}<0.001)$. The positive value for area indicates that $M$. mayori is more abundant in larger forest patches than in smaller ones. It should be noted, however, that this species also utilized smaller forest patches to a certain extent (Table 1). Although not significant, the shape index had a negative impact on this species indicating that it preferred more circular patches. In the case of the other predominant species $R$. rattus, only $10 \%$ of the variation was explained by the three factors, with none of the factors having a significant impact $(R$. rattus $=1.43-0.000025$ area -1.07 shape -0.117 isolation; $\mathrm{F}=0.43, \mathrm{P}>0.05)$. In the case of this too shape had a negative value indicating that it prefers circular forest patches. With regards to the Shannon-Weiner Diversity Index $\left[\mathrm{H}^{\prime}=-\sum(\mathrm{Pi} \ln \mathrm{Pi})\right]$ 
Table 1. Area, shape and distance to the nearest forest fragment of the selected forests and the species richness (S), abundance (number of species/individuals captured per 100 trap nights), abundance of the two predominant species Mus mayori $(\mathrm{Mm})$ and Rattus rattus $(\mathrm{Rr})$ and the diversity $\left(\mathrm{H}^{\prime}\right)$ and evenness $(\mathrm{E})$ values of the small mammal community of the fifteen rainforests. H' and E values are from the Shannon-Wiener Diversity Index.

\begin{tabular}{|c|c|c|c|c|c|c|c|c|c|}
\hline \multirow{2}{*}{ Forest } & \multirow{2}{*}{$\begin{array}{c}\text { Area } \\
\text { (ha) }\end{array}$} & \multirow{2}{*}{$\begin{array}{l}\text { Shape } \\
\text { Index }\end{array}$} & \multirow{2}{*}{$\begin{array}{l}\text { Distance to } \\
\text { the nearest } \\
\text { forest }(\mathrm{km})\end{array}$} & \multirow{2}{*}{$\mathbf{S}$} & \multicolumn{3}{|c|}{ Abundance } & \multirow[b]{2}{*}{$H^{\prime}$} & \multirow{2}{*}{$E$} \\
\hline & & & & & Total & $\mathrm{Mm}$ & $\mathbf{R r}$ & & \\
\hline Kanneliya & 6143.0 & 0.007 & 0.00 & 0.47 & 3.33 & 1.27 & 1.53 & 1.26 & 1.42 \\
\hline Kottawa & 2108.0 & 0.034 & 0.23 & 0.18 & 2.09 & 0.91 & 1.18 & 0.68 & 2.27 \\
\hline Dombagaslanda & 449.0 & 0.024 & 0.00 & 0.18 & 1.55 & 0.64 & 0.91 & 0.68 & 2.27 \\
\hline Kalugala & 4835.0 & 0.018 & 0.77 & 0.27 & 2.36 & 1.18 & 1.09 & 0.83 & 1.73 \\
\hline Morapitiya & 7108.0 & 0.010 & 0.84 & 0.27 & 3.18 & 1.45 & 1.55 & 0.81 & 1.69 \\
\hline Delwala & 1531.0 & 0.015 & 0.00 & 0.36 & 2.00 & 0.73 & 1.09 & 0.98 & 1.63 \\
\hline Delgoda & 1013.4 & 0.218 & 0.00 & 0.14 & 1.93 & 0.64 & 1.29 & 0.64 & 2.13 \\
\hline Dellawa & 2231.5 & 0.018 & 0.00 & 0.21 & 2.79 & 1.07 & 1.64 & 0.77 & 1.6 \\
\hline Masimbula & 299.2 & 0.004 & 0.45 & 0.29 & 2.43 & 0.71 & 1.57 & 0.48 & 0.8 \\
\hline Warathalgoda & 1940.0 & 0.026 & 0.00 & 0.36 & 2.73 & 1.09 & 1.45 & 0.93 & 1.55 \\
\hline Kalubowitiyana & 145.0 & 0.068 & 2.50 & 0.29 & 1.36 & 0.36 & 0.86 & 0.95 & 1.58 \\
\hline Sinharaja & 11000.0 & 0.009 & 0.00 & 0.57 & 3.14 & 1.57 & 0.71 & 1.49 & 1.66 \\
\hline Walankanda & 938.9 & 0.030 & 0.00 & 0.14 & 1.57 & 0.43 & 1.14 & 0.59 & 1.96 \\
\hline Yagirala & 2999.8 & 0.015 & 1.30 & 0.63 & 2.50 & 0.75 & 1.13 & 1.31 & 1.86 \\
\hline Kudumeriya & 2152.0 & 0.014 & 0.45 & 0.36 & 3.18 & 1.00 & 1.91 & 0.94 & 1.57 \\
\hline
\end{tabular}

or evenness $\left(\mathrm{E}=\mathrm{H}^{\prime} / \log \mathrm{S}\right)$ where $\mathrm{Pi}$ is the proportional abundance of a species in a forest and $\mathrm{S}$ is the species richness in that forest, the values show that Kanneliya, Sinharaja and Yagirala had distinctly higher diversity compared to the other forests (Table 1). In some forests (e.g. Dombagaskanda, Delgoda and Kottawa) although the diversity was low, the evenness values were high suggesting that the existing species were equally distributed.

Table 2 shows the abundance of the individual species in core and edge habitats of the 15 rainforests surveyed during the present investigation. Comparing the core and edge habitats of the forests, a total of eight species of small mammals were recorded from both core and edge habitats (Table 2). Of the 10 small mammals recorded, six species, the endemics $S$. ohiensis, M. mayori and $C$. miya and the nonendemics $R$. rattus, F. sublineatus and F. palmarum, were recorded from both core and edge habitats, while $F$. layardi and S. zeylanicus were recorded from only the core areas and the nonendemics M. booduga and Vandeleuria oleraceae were recorded only from edge habitats. With respect to overall abundance, both core areas and edges of forests recorded almost similar numbers of individuals (234 and 210). Similar results were noted for the abundance of small mammals in core and edge habitats when individual forests were considered $(\mathrm{T}=1.34, \mathrm{p}>0.05$, Pairwise $\mathrm{t}-\mathrm{Test})$. Marked differences were nevertheless evident when comparing the abundance of endemics and non-endemics. The abundance of endemics was higher in core areas than in the edge forests (123 core and 69 edge). This is primarily because of the differential use of interior and edge habitat by the endemic M. mayori. Significantly higher numbers of individuals were recorded for this species in core habitats (104 individuals) than at the edges (65 individuals). A reverse trend was seen for the non-endemics with more non-endemics using edges than interior areas. Some microhabitat features differed greatly between edges and core areas (Table 3). The core forest areas were characterized by a greater number of large trees, greater canopy cover, and by being shadier, cooler and more humid than the forest edges. The interior areas had a lower litter cover than edges. The forest edges, since they are exposed, have higher light levels and greater herbaceous vegetation. Statistical analyses revealed that four variables namely canopy cover, herbaceous cover, the number of large trees and litter cover differed significantly between the core and edge areas of the forest. 
Table 2. Species richness (S) and abundance (A) of the small mammal community and of the individual species in core areas and forest edges (in parentheses) of the 15 rainforests.

\begin{tabular}{|c|c|c|c|c|c|c|c|c|c|c|c|c|c|}
\hline Forest & $\begin{array}{c}\text { Trap } \\
\text { nights }\end{array}$ & $s$ & A & $\mathrm{Mm}^{*}$ & $\mathrm{Mb}$ & So* & $\mathbf{R r}$ & Vo & $\mathrm{Fl}^{*}$ & Fs & $\mathrm{Fp}$ & $\mathrm{Cm}^{*}$ & $\mathrm{Sz}^{*}$ \\
\hline \multirow{2}{*}{ Kanneliya } & 500 & 7 & 30 & 13 & - & 2 & 11 & - & 1 & 1 & - & 1 & 1 \\
\hline & & (3) & $(20)$ & (6) & & (1) & $(12)$ & & & & & 1 & \\
\hline \multirow{2}{*}{ Kottawa } & 500 & 2 & 13 & 7 & - & - & 6 & - & - & - & - & - & \\
\hline & & (2) & (10) & (3) & & & (7) & & & & & & \\
\hline \multirow{2}{*}{ Dombagaslanda } & 500 & 2 & 9 & 4 & - & - & 5 & - & - & - & - & - & \\
\hline & & (2) & (8) & (3) & & & (5) & & & & & & \\
\hline \multirow{2}{*}{ Kalugala } & 500 & 3 & 15 & 8 & - & - & 6 & - & - & - & - & 1 & \\
\hline & & (2) & (11) & (5) & 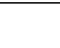 & & (6) & & 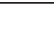 & 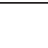 & 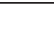 & & \\
\hline \multirow{2}{*}{ Morapitiya } & 500 & 3 & 21 & 11 & - & 2 & 8 & - & - & - & - & - & \\
\hline & & (2) & (14) & (5) & & & (9) & & & & & & \\
\hline \multirow{2}{*}{ Delwala } & 500 & 2 & 12 & 5 & - & - & 6 & - & - & (1) & - & - & \\
\hline & & (4) & $(10)$ & (3) & (2) & & (4) & & & & (1) & & \\
\hline \multirow{2}{*}{ Delgoda } & 800 & 2 & 15 & 5 & - & - & 10 & - & - & - & - & - & \\
\hline & & (2) & (12) & (4) & 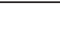 & . & (8) & & . & . & 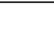 & . & \\
\hline \multirow{2}{*}{ Dellawa } & 800 & 2 & 15 & 8 & - & - & 7 & - & - & - & - & - & - \\
\hline & & (3) & (24) & (7) & 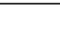 & & (16) & & & (1) & & & \\
\hline \multirow{2}{*}{ Masimbula } & 800 & 3 & 17 & 6 & - & 1 & 10 & & & & & & \\
\hline & & (3) & (17) & 4 & 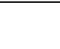 & 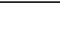 & (12) & & . & & (1) & & \\
\hline \multirow{2}{*}{ Warathalgoda } & 500 & 2 & 16 & 8 & - & - & 8 & - & - & - & - & - & - \\
\hline & & (4) & (14) & (4) & (1) & 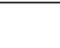 & (8) & - & 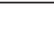 & 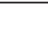 & & (1) & \\
\hline \multirow{2}{*}{ Kalubowitiyana } & 800 & 3 & 9 & 2 & - & - & 6 & - & - & - & 1 & - & - \\
\hline & & (3) & (10) & (3) & & & $(6)$ & & & & & (1) & \\
\hline \multirow{2}{*}{ Sinharaja } & 800 & 7 & 36 & 15 & - & 3 & 5 & - & 2 & 2 & - & 2 & 1 \\
\hline & & (4) & (14) & (7) & 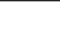 & (1) & (5) & & & & (1) & & \\
\hline \multirow{2}{*}{ Walankanda } & 800 & 2 & 8 & 3 & - & - & 5 & - & - & - & - & - & - \\
\hline & & (2) & (14) & 3 & . & & (11) & & & & & & \\
\hline \multirow{2}{*}{ Yagirala } & 800 & 2 & 7 & 4 & - & - & 3 & - & - & - & - & - & - \\
\hline & & (5) & (13) & $(2)$ & (1) & & (6) & (1) & & & (3) & & \\
\hline \multirow{2}{*}{ Kudumeriya } & 500 & 4 & 17 & 5 & & & 10 & & & & 1 & 1 & \\
\hline & & (3) & (18) & (6) & & & (11) & & & & (1) & & \\
\hline
\end{tabular}

Mm - Mus mayori; Mb - Mus booduga; So - Srilankamys ohiensis; $\mathrm{Rr}$ - Rattus rattus; Vo - Vandeleuria oleraceae; FI - Funambulus layardi; Fs - F. sublineatus; Fp - F. palmarum; Cm - Crocidura miya and Sz - Suncus zeylanicus. * - Endemic species

\section{DISCUSSION}

The present survey was conducted with the objective of investigating the overall effects of forest fragmentation on small mammal communities inhabiting the remnant rainforest patches in Sri Lanka. The theory of island biogeography by MacArthur \& Wilson (1967) predicts that larger areas would support greater numbers of species and individuals than smaller areas. Supporting this claim, Goodman
\& Rakotondravony (2000) report that in Madagascar, the species of the families Tenrecidae and Soricidae declined progressively with diminishing forest size. Similarly, Schoener (1974) proposed that, for small mammals, space is the main niche dimension that facilitates the coexistence of ecologically similar species. It has been shown that larger spaces result in greater resource diversity making the coexistence of a large number of species feasible (Vieira \& MonteiroFilho 2003; Renata 2004). Also, it is reported that 
Table 3. Habitat variables (mean \pm std. error) in core and edge habitats in the surveyed rainforests. Results of the pairwise t-Tests comparing the mean values of each parameter in core and edge habitats of the individual forests are also shown.

\begin{tabular}{|l|c|c|c|c|c|}
\hline Habitat feature & Core & Edge & $\mathbf{n}$ & $\mathbf{T}$ & $\mathbf{P}$ \\
\hline \% Canopy cover & $93.57 \pm 1.22$ & $89.78 \pm 1.60$ & 15 & 2.14 & $0.050^{*}$ \\
\hline Number of seedlings & $15.94 \pm 2.24$ & $15.22 \pm 2.66$ & 15 & 0.56 & 0.583 \\
\hline Number of herbs & $29.35 \pm 4.88$ & $41.70 \pm 5.32$ & 15 & -3.64 & $0.003^{* *}$ \\
\hline Number of plants & $53.00 \pm 6.28$ & $51.40 \pm 8.94$ & 15 & 0.45 & 0.662 \\
\hline Number of large trees & $6.40 \pm 0.50$ & $4.50 \pm 0.48$ & 15 & 4.34 & $0.001^{* * *}$ \\
\hline Litter depth & $2.81 \pm 0.11$ & $2.56 \pm 0.17$ & 15 & 1.37 & 0.190 \\
\hline$\%$ Litter cover & $93.48 \pm 1.84$ & $95.86 \pm 1.00$ & 15 & -2.16 & $0.050^{*}$ \\
\hline Light intensity & $548.5 \pm 73.5$ & $621.3 \pm 60.5$ & 13 & -1.43 & 0.178 \\
\hline Relative humidity & $84.84 \pm 1.62$ & $83.93 \pm 1.46$ & 11 & -1.93 & 0.082 \\
\hline Air temperature $\left({ }^{\circ} \mathrm{C}\right)$ & $25.2 \pm 0.45$ & $25.9 \pm 0.37$ & 11 & 1.15 & 0.263 \\
\hline
\end{tabular}

${ }^{*}=\mathrm{P}<0.05 ;{ }^{* *}=\mathrm{P}<0.01 ;{ }^{* * *}=\mathrm{P}<0.001$

the reduction of species is such that the complement of species in smaller patches is a subset of that found in larger ones (e.g. Patterson \& Brown 1991; Pattanavibool \& Dearden 2002).

The species-area relationship per se, however, does not consider a variety of other factors that are of considerable importance in determining the viability of species and populations within habitat islands. For instance, fragmentation facilitates the creation of edge habitats that in turn may seriously affect the diversity of organisms within the forest patches (Laurance 1991; Hansen et al. 1992). The type of habitat matrix surrounding the individual forest patches will also have an impact on diversity (Renata 2004). The degree of isolation also influences the viability of the species within a particular fragment (Kozakiewicz \& Jurasinska 1989). Hence, the variability of these factors between forest fragments may serve to mask the effects of area on biotic communities. This is evident from the results of several studies - Lindenmayer et al. (2000) for mammals; Wethered \& Lawes (2003) for birds; Conde \& Rocha (2006) and Rosenblatt et al. (1999) for small mammals.

The present study did not provide direct evidence for the species-area relationship. It is apparent from the results of the present study that the lack of a species-area relationship for the overall small mammal community is because the absence of, or the reduction in, certain species in smaller fragments was well compensated for by other species. These "replacement species", are those that are more adaptable to man modified landscapes. This observation suggests that a species replenishment model, demonstrated in some studies (e.g. Harraington et al. 2001; Castelletta et al. 2005), is applicable to the rainforests in Sri Lanka. Several studies have in fact shown that the speciesarea theory may be applicable at a regional scale but is not applicable at smaller spatial scales (Cutler 1991; Patterson \& Brown 1991). Middleton \& Merriam (1983), working with small mammal fauna of forest fragments in Illinois, likewise claim that the island biogeography analogy does not apply well for the areas studied.

Species replacement tends to obscure speciesarea relationships. The patterns of replacement of species in smaller fragments in turn reflect the species' ability to tolerate edge effects (Yáñez et al. 1999). Andrén (1994) reports that species' responses to habitat disturbance are varied with fragmentation and edge effects imposing major threats to the survival of forest-dependent fauna. He further states that habitat generalists were largely tolerant of habitat fragmentation, their abundance being similar in forests, corridors, and remnants, and are capable of persisting in remnants only a few hectares in extent. In the present study the patterns of occupancy of the two predominant species, the endemic $M$. mayori and the cosmopolitan $R$. rattus in particular, clearly demonstrate such differences in tolerance. The fact that the smallest fragments and forest edges were occupied by a lesser number of individuals of M. mayori strongly suggests that environmental conditions in edges were perceived as matrix rather than a forest habitat by this species. It was evident from the results of the present 
investigation that the forest interior was much cooler and had different vegetation characteristics such as greater canopy cover and larger trees and lesser herbaceous cover, than the edge habitats. $R$. rattus, in contrast to the former, is a ubiquitous generalist species that has managed to colonize six continents and thousands of islands in the wet tropics as well as in arid environments. In addition to $M$. mayori, the fact that the endemics $S$. ohiensis and $F$. layardi and the non-endemic F. sublineatus preferentially utilized interior areas, suggest that they may be negatively affected by the creation of habitat edges. On the other hand, those that are tolerant of habitat edges and perhaps benefit by such human modifications are $R$. rattus, $M$. booduga and $F$. palmarum.

Due to edge effects and the differential tolerance of species, the shape of a particular forest patch could be expected to influence the biotic community it supports. Circular forest patches will have proportionately less edge habitat than similar-sized linear forest patches (Bentley et al. 2000). The shape index for forest fragments is calculated as the ratio of perimeter to area (Gkaraveli et al. 2001), which increases as forests become more linear. Based on this premise, the abundance of core forest species should be negatively affected by the shape index, which was observed for M. mayori.

Althoughthe fragmentationofSriLankan rainforests may not have an overall impact on the species richness of the small mammal community the study clearly demonstrates that it may lead to the decline of certain forest-adapted species. This emphasizes the need to preserve large intact and circular forests whenever possible. The preservation of the smaller forests is also important, since they function as potential "stop over points" that may facilitate the spreading of forest species to nearby patches. Such linkages between forests are particularly important for small mammals that are unable to cover large distances.

\section{REFERENCES}

Andrén, H. (1994). Effects of habitat fragmentation on birds and mammals in landscapes with differed proportions of suitable habitat: a review. Oikos 71: 355-366.

Bentley, J.M., C.P. Catterall \& G.C. Smith (2000). Effects of fragmentation of Auraucarian vine forest on small mammal communities. Conservation Biology 14: 1075-1087.
Boone, J.D. \& B.L. Keller (1993). Temporal and spatial patterns of small mammal density and species composition in a radioactive waste disposal area: The role of edge habitat. Great Basin Naturalist 53: 341-349.

Castelletta, M., J.M. Thiollay \& N.S. Sodhi (2005). The effects of extreme forest fragmentation on the bird community of Singapore Island. Conservation Biology 121: 135-155.

Cincotta, R.P., J. Wisnewski \& R. Engleman (2000). Human population in the biodiversity hotspots Nature 440: 990 992.

Conde, C.F. \& C.F.D. Rocha (2006). Habitat disturbance and small mammal richness and diversity in an Atlantic rainforest area in southeastern Brazil. Brazilian Journal of Biology 66: 983-990.

Cox, M.P., C.R. Dickman \& J. Hunter (2004). Effects of rainforest fragmentation on non-flying mammals of the Eastern Dorrigo Plateau, Australia. Biological Conservation 115: $175-189$.

Cutler, A. (1991). Nested faunas and extinction in fragmented habitats. Conservation Biology 5: 496-505.

Debinski, D.M. \& R.D. Holt (2000). A survey and overview of habitat fragmentation experiments. Conservation Biology 14: $342-355$

de Rosayro, R.A. (1950). Ecological conceptions and vegetation types with special reference to Ceylon. The Tropical Agriculturist 56: 108-121.

Diffendorfer, J.E., M.S. Gaines \& R.D. Holt (1995). Habitat fragmentation and movements of three small mammals (Sigmodon, Microtus and Peromyscus). Ecology 76: 827839.

Gkaraveli, A., J.H. Williams \& G.E.G. Good (2001). Fragmented native woodlands in Snowdonia. UK: Assessment and amelioration. Forestry 74: 89-193.

Goodman, S.M. \& D. Rakotondravony (2000). The effect of forest fragmentation and isolation on insectivorous small mammals (Lipothyphla) on the Central High Plateau of Madagascar. Journal of Zoology 250: 193-200.

Hansen, A.J., P.G. Risser \& F. DiCastri (1992). Epilogue: Biodiversity and ecological flows across ecotones, pp. 423-438. In: Hansen, A.J. \& F. DiCastri (eds.). Landscape boundaries. Consequences for Biotic Diversity and Ecological Flora. Springer-Verlag, New York.

Harraington, G.N., A.N.D. Freeman \& F.H.G. Crome (2001). The effects of fragmentation of an Australian tropical rainforest on populations and assemblages of small mammals. Journal of Tropical Ecology 17: 225-240.

KozAkiewicz, M. \& E. Jurasinska (1989). The role of habitat barriers in woodlot recolonizatin by small mammals. Ecography 12: 106-111.

Laurance, W.F. (1991). Edge effects on tropical forest fragments. Application of a model for the design of nature reserves. Biological Conservation 57: 205-219.

Laurance, W.F., P. Delamônica, S.G. Laurance, H.L. Vasconcelos \& T.E. Lovejoy (2000). Rainforest fragmentation kills big trees. Nature 404: 836 .

Lindenmayer, D.B., M.A. McCarthy, K.M. Parris \& M. 
Pope (2000). Habitat fragmentation, landscape context and mammalian assemblages in south-eastern Australia. Journal of Mammalogy 82: 787-797.

MacArthur, R.H. \& E.O. Wilson (1967). The Theory of Island Biogeography. Princeton University Press, Princeton, 203pp.

Malcolm, J.R. (1994). Edge effects in central amazonian forest fragments. Ecology 75: 2438-2445.

Middleton, J. \& G. Merriam (1983). Distribution of woodland species in farmland woods. Journal of Applied Ecology 20: 625-644

Molur, S. \& M. Singh (2009). Non-volant small mammals of the Western Ghats of Coorg District, southern India. Journal of Threatened Taxa 1(12): 589-608.

Myers, N. (1990). The biodiversity challenge: Expanded hotspot analysis. The Environmentalist 10: 243-256.

Myers, N., R.A. Mittermeir, C.G. Mittermeir, G.A.B. da Fonseka \& J. Kent (2000). Biodiversity hotspots for conservation priorities. Nature 403: 853-858.

Pattanavibool, A. \& P. Dearden (2002). Fragmentation and wildlife in montane evergreen forests, northern Thailand. Biological Conservation 107: 155-164.

Patterson, B.D. \& J.H. Brown (1991). Regionally nested patterns of species composition in granivorous rodent assemblages. Journal of Biogeography 18: 395-402.

Ratnaweera, P.B. \& M.R. Wijesinghe (2009). Effect of food quality and availability on rainforest rodents of Sri Lanka. Journal of Threatened Taxa 1(12): 581-588.

Renata, P. (2004). Effects of forest fragmentation on small mammals in an Atlantic forest landscape. Biodiversity Conservation 13: 2567-2586.

Rosenblatt, D.L., E.J. Heske, S.L. Nelson, D.M. Barber, M.A. Miller \& B. MacAllister (1999). Forest fragments in east-central Illinois: islands of habitat fragments for mammals? American Midland Naturalist 141: 115-123.

Schoener, T.W. (1974). Competition in the form of habitat shift. Theoretical Population Biology 6: 265-307.

Vieira, E.M. \& E.L.A. Monteiro-Filho (2003). Vertical stratification of small mammals in the Atlantic rainforest of south-eastern Brazil. Journal of Tropical Ecology 19: 501-507.

Walters, B.B. (1991). Small mammals in subalpine old-growth forest and clearcuts. Northwest Science 65: 27-31.

Wethered, R. \& M. Lawes (2003). Matrix effects on bird assemblages in fragmented Afromontane forests in South Africa. Biological Conservation 114: 327-340.

Wijesinsghe, M.R. (2010). Efficiency of live trapping protocols to assess small mammal diversity in tropical rainforests of Sri Lanka. Belgian Journal of Zoology 140: 212-215.

Wijesinghe, M.R. \& M. de Brooke (2005). The distribution of small mammals along a disturbance gradient in Sinharaja, Sri Lanka. Journal of Tropical Ecology 21: 291-296.

Yahner, R.H. (1988). Changes in wildlife communities near edges. Conservation Biology 2: 333-339.

Yáñez, M.A., V. Frida, J.A. Simonetti \& A.A. Grez (1999). Small mammals of forest islands of the Beni Biological Station, Bolivia. Mastozoología Neotropical 6: 135-138. 